\title{
QUANTIFYING RELATIONSHIPS BETWEEN BIRD AND BUTTERFLY COMMUNITY SHIFTS AND ENVIRONMENTAL CHANGE
}

\author{
Diane M. Debinski, ${ }^{1}$ Ron E. VanNimwegen, ${ }^{1}$ And Mark E. Jakubauskas ${ }^{2}$ \\ ${ }^{1}$ Department of Ecology, Evolution, and Organismal Biology, Iowa State University, Ames, Iowa 50011 USA \\ ${ }^{2}$ Kansas Applied Remote Sensing (KARS) Program, University of Kansas, Lawrence, Kansas 66047 USA
}

\begin{abstract}
Quantifying the manner in which ecological communities respond during a time of decreasing precipitation is a first step in understanding how they will respond to longer-term climate change. Here we coupled analysis of interannual variability in remotely sensed data with analyses of bird and butterfly community changes in montane meadow communities of the Greater Yellowstone Ecosystem. Landsat satellite imagery was used to classify these meadows into six types along a hydrological gradient. The northern portion of the ecosystem, or Gallatin region, has smaller mean patch sizes separated by ridges of mountains, whereas the southern portion of the ecosystem, or Teton region, has much larger patches within the Jackson Hole valley. Both support a similar suite of butterfly and bird species. The Gallatin region showed more overall among-year variation in the normalized difference vegetation index (NDVI) when meadow types were pooled within regions, perhaps because the patch sizes are smaller on average. Bird and butterfly communities showed significant relationships relative to meadow type and NDVI. We identified several key species that are tightly associated with specific meadow types along the hydrological gradient. Comparing taxonomic groups, fewer birds showed specific habitat affinities than butterflies, perhaps because birds are responding to differences in habitat structure among meadow types and using the landscape at a coarser scale than the butterflies. Comparing regions, the Teton region showed higher predictability of community assemblages as compared to the Gallatin region. The Gallatin region exhibited more significant temporal trends with respect to butterflies. Butterfly communities in wet meadows showed a distinctive shift along the hydrological gradient during a drought period (1997-2000). These results imply that the larger Teton meadows will show more predictable (i.e., static) species-habitat associations over the long term, but that the smaller Gallatin meadows may be an area that will exhibit the effects of global climate change faster.
\end{abstract}

Key words: butterflies; climate change; community structure; discriminant analysis; environmental variation; normalized difference vegetation index (NDVI); ordination; songbirds; species composition.

\section{INTRODUCTION}

As scientists explore the implications of global climate change, much of the focus has been on abiotic factors such as carbon fluxes and atmospheric composition. Studies are emerging that reflect shifts in community composition and phenology, poleward distributional shifts, and extinction risks due to climate change (Brown et al. 1997, Parmesan et al. 1999, Fitter and Fitter 2002, Parmesan and Yohe 2003, Root et al. 2003, Thomas et al. 2004). Changes in ecological (biotic) communities are one of the many possible consequences of environmental change. Understanding the manner in which species respond to short-term variations in climate in pristine environments may allow us to extrapolate to larger regions or longer time periods. The methodology for predicting potential ecological effects of climate change, however, is not well devel-

Manuscript received 20 December 2004; revised 8 April 2005; accepted 28 April 2005. Corresponding Editor: M. Friedl. oped because the number of high-quality, long-term ecological data sets is still somewhat limited.

Climate change models predict warmer temperatures, lower snowfall, and drier conditions (Romme and Turner 1991) as well as increased variability in both temperature and precipitation (McLaughlin et al. 2002) for montane ecosystems in the Rocky Mountain region. Montane meadows, defined here as persistently nonforested habitats in mountain ecosystems, encompass a broad hydrological gradient, from hydric (e.g., sedge and willow) to xeric (e.g., sagebrush) sites. The seasonal and interannual variation in spring onset of photosynthetic activity and vegetation condition in these meadows is detectable using remotely sensed satellite imagery (Debinski et al. 2000). Ecologically, montane meadows are inhabited by short-lived plants and highly mobile animal species that can exhibit quick responses to changes in the environment. They are also some of the most pristine and biologically diverse areas in the United States. Our goal was to quantify interannual landscape-level and ecological variability in montane 


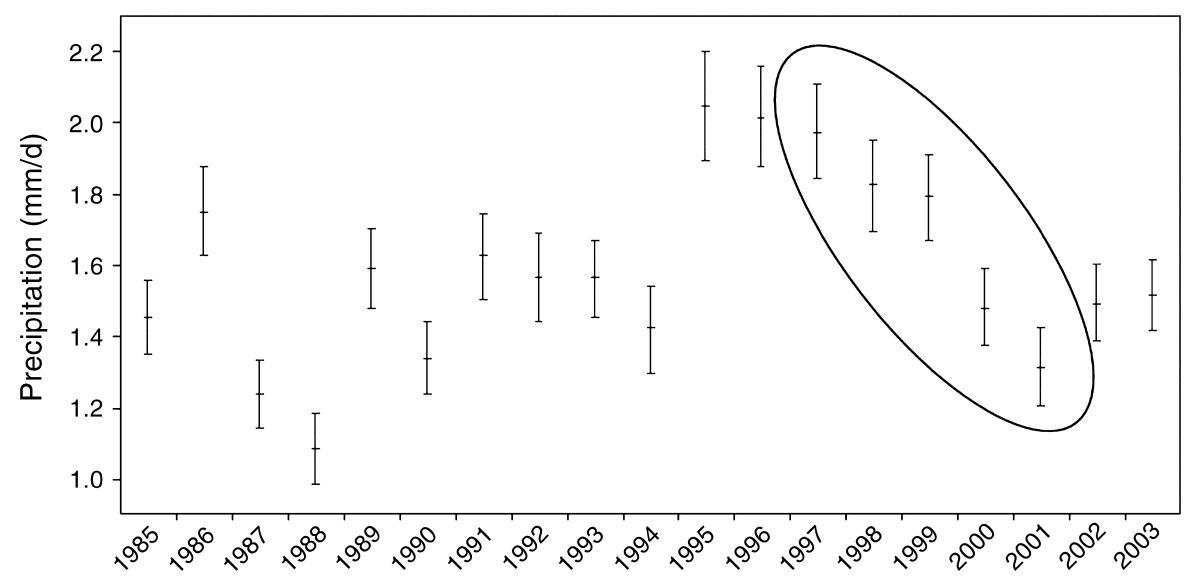

FIG. 1. Daily precipitation in the study area from 1985 to 2003 (means \pm SE). Note the general drying trend from 1996 to $2001\left(R^{2}=0.64, P<0.001\right)$. We used three weather stations (Stations 240775, Big Sky; Station 485345, Lake Yellowstone; and Station 486440, Moran 5WNW) to represent the extent of the Greater Yellowstone Ecosystem, USA, study region.

meadow communities during a time when local annual precipitation was declining (1997-2001; Fig. 1). The central hypothesis for the research was that landscapelevel variables (e.g., land cover type as characterized using remotely sensed data) and ecological response variables (e.g., species' distribution patterns) are particularly sensitive to climate variations and thus will exhibit early responses to regional climate change.

We have been studying montane meadow biodiversity of plants, birds, and butterflies annually in the Greater Yellowstone Ecosystem (GYE) since 1992 (Debinski et al. 1999, 2000). We have used satellite imagery to classify meadow types along a moisture gradient (from hydric to mesic to xeric). At the midpoint of the moisture gradient, mesic meadows have the highest magnitude of seasonal and interannual variation in spectral reflectance (a surrogate for aboveground photosynthetically active biomass) (Debinski et al. 2000). These mesic meadows also support the highest species diversity of plants and butterflies (Debinski et al. 2000). Bird diversity is highest in the hydric meadows.

Our first objective was to document interannual variability in montane meadow patch conditions using remotely sensed data. We used remotely sensed data as a landscape-scale surrogate for processes occurring within the ecosystem. A "patch" was defined here as a homogenous area of one meadow type, as classified by satellite data. Meadow types were classified using remotely sensed data, classifications were validated by fieldwork, and vegetation condition was assessed annually using the normalized difference vegetation index (NDVI $=$ [near-infrared reflectance - red reflectance]/[near-infrared reflectance + red reflectance]; Jensen 2000). We hypothesized that smaller meadows, especially in the hydric to mesic range, would exhibit greater interannual variability in spectral response. Because smaller meadows have a larger edge-to-area ratio, they have a smaller "mass" from which to maintain internal conditions. We expected that this higher var- iability might imply that smaller patches are more vulnerable to shifting to a new point along the hydrological gradient under climate change. Since our NDVI calculations were site- and year-specific, we could statistically relate those values directly to the community data we collected at those sites. The National Climate Data Center (NCDC) climate data was only regional. Therefore, we used changes in NDVI as a method to quantify the effects of changing climatic conditions within each meadow type. Large-scale studies have shown strong correlations between NDVI and seasonal weather patterns, especially precipitation (Schultz and Halpert 1993, Yang et al. 1997, 1998).

Our second objective was to link species distributions from a single-species perspective and a community perspective to each of these meadow types. Although previous community studies, for example with butterflies, have predicted species occurrence patterns in relation to environmental variables such as elevational gradients (e.g., Fleishman et al. 2001, 2003), we did not know whether ecological communities would also reflect differences based upon meadow types separated by remotely sensed data. We chose species from two distinct and commonly studied taxonomic groups that were both high in species diversity (birds and butterflies). We hoped to identify species showing strong habitat affinities with particular meadow types along the hydrological gradient or that show distinctive trends of maximum abundance at particular points along the hydrological gradient. Finally, we wanted to document temporal changes in species composition patterns relative to changes in habitat condition. We expected butterflies to respond quickly to climate change because they respond to the condition of the vegetation (moisture level, biomass, nectar production), whereas birds were expected to change more slowly because they respond more to the structure of the vegetation (Salt 1957, Knopf and Sedgewick 1992). Previous studies have indicated that a decrease in 
NDVI is correlated with lower plant moisture levels and lower biomass (e.g., Teng 1990) and such changes are likely to be associated with lower nectar production. All of these vegetation changes could have negative consequences for both caterpillars and butterflies, which feed directly on the vegetation. Birds may have less of a direct response, but decreased NDVI could be associated with reduced avian food supply via decreased seed production or insect abundance. There is also evidence that birds respond to vegetation composition and floristics (Wiens and Rotenberry 1981, Rotenberry 1985, Wiens et al. 1987). We hypothesized that species would show interannual shifts in abundance that were correlated with habitat changes. For example, we expected that as mesic sites became more xeric during hotter, drier years, mesic butterfly communities would shift to sites that had previously been considered more hydric sites.

Multispectral satellite remote sensing provides a powerful means for detecting and characterizing environmental changes at multiple spatial and temporal scales. Analysis of changing spectral patterns can provide precursor measurements of terrestrial ecosystem dynamics (Ustin et al. 1993, Lancaster et al. 1996). Time series analysis of multispectral imagery has allowed scientists to examine phenological phenomena such as spring onset of photosynthetic activity, duration of green period, onset of senescence, and change in seasonally dependent biophysical variables such as leaf area index, biomass, and net primary productivity (Roller and Colwell 1986, Becker and Choudhury 1988, Gallo and Eidenshink 1988, Achard and Blasco 1990, Teng 1990). Similarly, there is a plethora of papers examining remote sensing applications to predicting presence of one species or a number of species individually (e.g., Cardillo et al. 1999, Kerr et al. 2001, Hepinstall et al. 2002). Environmental assessment programs are increasingly linking remotely sensed imagery, digital elevation models, and field information to integrate descriptions of small-scale processes up to regional and global scales (O’Neill et al. 1997). By calibrating remotely sensed multispectral data with ground measurements of biotic properties, habitat condition (e.g., biomass, percent cover, nectar resources) measured at sample points can be extrapolated across a large geographic region (Graetz 1990). Here we extend this process of calibration and extrapolation by developing a remote sensing-based measure of habitat variation and relating this measure to species composition patterns.

The tightly constrained ecosystem of the montane meadows provides an excellent model for examining interannual variability in ecological communities. The vegetation of montane meadows is an essential component of the data collection and analysis. Vegetation is a component part of the ecological community, but it is also a component of the habitat for the bird and butterfly communities. Individual plant species have a range of hydrological conditions and soils under which they can persist, and we expected those adapted to hydric conditions to exhibit ranges reflecting local hydrology. Birds and butterflies are representatives of the primary and secondary consumer levels. Both taxa show a high diversity of species and can respond quickly to changes in environmental conditions. Butterflies respond to microhabitat, plant structure, and plant chemical composition. More than 100 species of butterflies occur in the Yellowstone ecosystem (Debinski and Pritchard 2002), and many are closely correlated with specific meadow habitats (Debinski et al. 2001). Further, a strong connection between climate and butterflies has been recognized by many authors (e.g., Pollard and Yates 1995, Warren 1999). The implications of changes in climate for butterflies are potentially serious (Dennis 1993), and particular concern has been expressed about montane butterfly communities where habitats are predicted to contract (Pullin 1995). Bird communities reflect the condition of many aspects of the ecosystem and often respond to spatial and temporal variation in a species-specific fashion (Steele et al. 1984, Taper et al. 1995). Moreover, they are conspicuous, ubiquitous, intensively studied, and often appear to be more sensitive to environmental changes than other vertebrates (Morrison 1986). We have found strong relationships between the songbird community and each of the specific meadow types in the ecosystem (Saveraid et al. 2001).

Many previous attempts to define evidence of environmental change have failed because of their narrow focus, utilizing one or a few species (Cairns 1986, Landres et al. 1988, Kremen 1992) or only addressing one ecological level of response. From the perspective of climate change assessment, many papers document or predict abiotic environmental changes as a consequence of climate change. For example, Lighthill et al. (1994) predict increased cyclone activity, Pavlidis and Shcherbakov (2002) have modeled future coastline changes, and a host of mechanisms were proposed that link precipitation changes to differing patterns of soil erosion (Nearing 2001, Nearing et al. 2004). Our approach is novel in that we assess landscape changes (abiotic) and link them to changes across multiple taxonomic groups (biotic) at the level of the ecological community during a time when precipitation is decreasing.

\section{Methods}

\section{Image selection}

A seasonal series of Landsat Thematic Mapper (TM) multispectral satellite imagery during the snow-free period was used to assess interannual variability in meadow condition from 1996 to 2002. One scene of Landsat TM data was selected for each year during the height of the growing season (mid-July). We chose the following scene dates, each of which represented minimal 
cloud cover and a midpoint in the annual growing season: 15 July 1997, 18 July 1998, 23 July 2000, and 2 July 2001. Each scene had a resolution of $30 \mathrm{~m} /$ pixel and consisted of six bands within the reflective opticalrange electromagnetic spectrum (blue, green, red, nearinfrared, two middle-infrared). The thermal band was not used in our analysis.

\section{Sampling sites}

We have built an extensive database of plant, butterfly, and bird community data and remotely sensed data from 1996 to 2002 (e.g., Jakubauskas et al. 1998, Kindscher et al. 1998, Debinski et al. 1999, 2002) in two regions of the ecosystem: the northern "Gallatins", region that includes the Gallatin National Forest and northwestern portion of Yellowstone National Park; and the southern "Tetons" region that includes Grand Teton National Park and the Bridger-Teton National Forest. The two regions have very distinct landscapes and differ significantly in patch size (Debinski et al. 2001), but support similar meadow types and plant, bird, and butterfly diversity.

Sampling sites were identified using remotely sensed classification of the montane meadow habitats to identify a moisture gradient in montane meadows (Jakubauskas and Debinski 1995). These sites comprised a hydrologic gradient and were classified into six meadow types (hereafter termed $M$ types), ranging from extremely hydric (M1) to extremely xeric (M6) meadows. Field investigations confirmed the moisture gradient predicted for the meadows (Jakubauskas et al. 1998, Kindscher et al. 1998, Debinski et al. 2000). M1 and M2 meadows are willow (Salix spp.) thickets and sedge (Carex spp.) marshes, respectively, with some standing water. M3 meadows are mesic meadows characterized by diverse forb and grass coverage. M4 meadows are of medium moisture with cinquefoil (Potentilla spp.) and mixed herbaceous vegetation, while M5 meadows have a mixture of sagebrush (Artemesia tridentata) and herbaceous vegetation. M6 meadows are characteristically xeric, rocky, and dominated by sagebrush. Field sampling was used to collect data on the distribution of plant, bird, and butterfly species. Five sites of each $M$ type were established in each region, but no M4s were found in the Tetons. Therefore, we sampled 30 sites in the Gallatins and 25 sites in the Tetons.

\section{Radiometric normalization and NDVI calculations}

Each 30-m resolution image was geographically referenced using a cubic convolution transformation and four widely spaced control points. We then used a simple regression technique (Jensen 1983, Yuan and Elvidge 1996) for relative radiometric normalization, using our 1997 image as a baseline. As with most radiometric normalization methods, our procedure required the selection of time-invariant reference points; that is, locations where pixel values should not vary among years (Furby and Campbell 2001, Du et al. 2002). When such points do vary among years, the change can be attributed to non-landcover reflectance causes, such as atmospheric variation or satellite sensor differences. Our invariant points consisted of three general landcover types: water, gravel/rock, and shaded forest.

We only inspected bands 3 (red) and 4 (near infrared), because these were the bands used to calculate the normalized vegetation difference index (NDVI). Band 4 showed minimal differences among years, while band 3 showed an approximately 50\% increase in pixel values across all invariant targets, but only in the 2001 image. This was a Landsat 7 Enhanced Thematic Mapper Plus (ETM+) image, while the 1997, 1998, and 2000 images were Landsat 5 Thematic Mapper (TM) images. Therefore, we suspect the differences were due to sensor types rather than temporal atmospheric changes. Once we had "corrected" bands 3 and 4 of our 1998, 2000, and 2001 images by applying the linear regression functions, we proceeded to calculate the NDVI values of our study sites.

For each scene, we calculated the NDVI of a $90 \times$ $90 \mathrm{~m}$ ground area $(3 \times 3$ pixels $)$ centered in each of our 55 sites. Thus, the NDVI calculation applied to the area directly sampled for plants, birds, and butterflies. We did not sample larger areas in larger meadows, but focused solely on a constant total area for both our satellite data analysis and ecological community data. To streamline the process, we used Erdas Imagine version 8.2 (Leica Geosystems Geospatial Imaging, Norcross, Virginia, USA) to apply a $3 \times 3$ low-pass convolution filter to each image. This filter averaged each pixel value with its eight surrounding pixels and used the resultant values to create a new image. From that image, we extracted the site-specific pixel values for bands 3 and 4 to perform the NDVI calculations for each site (NDVI for Landsat TM = [band $4-$ band 3]/[band $4+$ band 3]). We used site-specific NDVI values in our subsequent bird and butterfly community analyses. We also averaged the NDVI values across sites for each meadow type and plotted the interannual changes over the four-year period (Figs. 2 and 3). We also examined the effects of $\mathrm{M}$ type, region, and year (as a categorical value) using ANOVA and Tukey's honestly significant difference (HSD) test.

\section{Climate data}

We obtained daily climate data for the GYE area from the NCDC. We chose three weather stations (Station 240775, Big Sky; Station 485345, Lake Yellowstone; and Station 486440, Moran 5WNW) to represent the extent of the GYE and acquired the daily precipitation data for each station for 1985 to 2003. We averaged the daily values across stations, thus eliminating the gaps in climate data that can result from an occasional malfunctioning weather station. This data set provided a long-term context within which we could assess the relative precipitation changes that occurred during our study period (Fig. 1). 


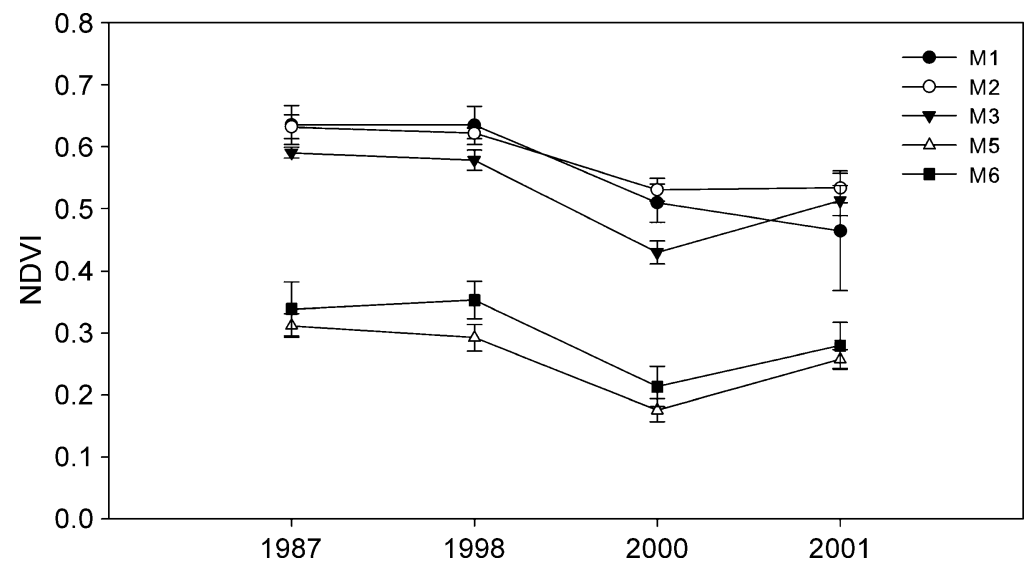

FIG. 2. Interannual normalized difference vegetation index (NDVI) change in 25 Gallatin sites from 1997 to 2001 (without 1999), based on Landsat imagery (means \pm SE). In general, wet meadows (M1-M2) show higher mean NDVI values than dry meadows (M5-M6).

\section{Identifying species-habitat associations}

We conducted plant, bird, and butterfly surveys each summer from 1997 to 2001 (excluding 1999, when our sampling efforts were diverted to a related study). Two taxa and two regions provided four taxon-region data sets for individual analyses. Since there were no M4s found in the Tetons based on our classification scheme, we only used Gallatin data sets after removing M4s. With 25 sites in each region and four years of surveys, each taxon-region data set consisted of 100 "siteyears.",

We have focused our analysis here on the birds and butterflies because the plant community is summarized indirectly by changes in NDVI. Further, we analyzed percent cover data of the 25 most dominant plant species at each site using $20 \times 20 \mathrm{~m}^{2}$ sampling units (see Debinski et al. [1999] for sampling methods) from 1997, 1998, and 2001, and ordinations did not show any temporal change (D. M. Debinski, unpublished data). Thus, we infer that NDVI change among years was more a reflection of changes in moisture level or productivity than changes in species composition of the plant community.

For bird and butterfly community analysis, we removed all rare species, that is, those whose total relative abundance for the entire study period was $<10$. For a given site and year, relative abundance was calculated as the total number of a species divided by the number of surveys performed. We also removed species not identified to the species level. For birds, we removed colonial bird species such as swallows that were probably not using the area for nesting, but rather foraging there on a temporary basis. Similarly, we removed "flyover" species that were seen but never stopped in the site as we were sampling. This winnowing of the data allowed our songbird data set to focus on birds breeding within the meadows. Our resultant data set consisted of 17 total bird species (10 in the Gallatins and 16 in the Tetons) and 30 butterfly species (23 in each region).

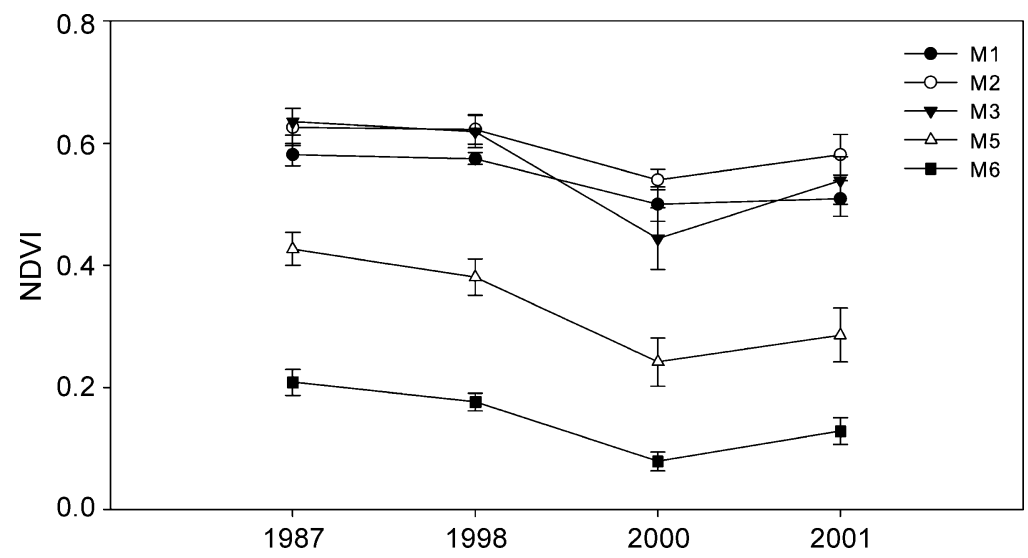

FIG. 3. Interannual normalized difference vegetation index (NDVI) change in 25 Teton sites from 1997 to 2001 (without 1999), based on Landsat imagery (means \pm SE). In general, wet and mesic meadows (M1-M3) show higher NDVI values than dry meadows (M5-M6). 


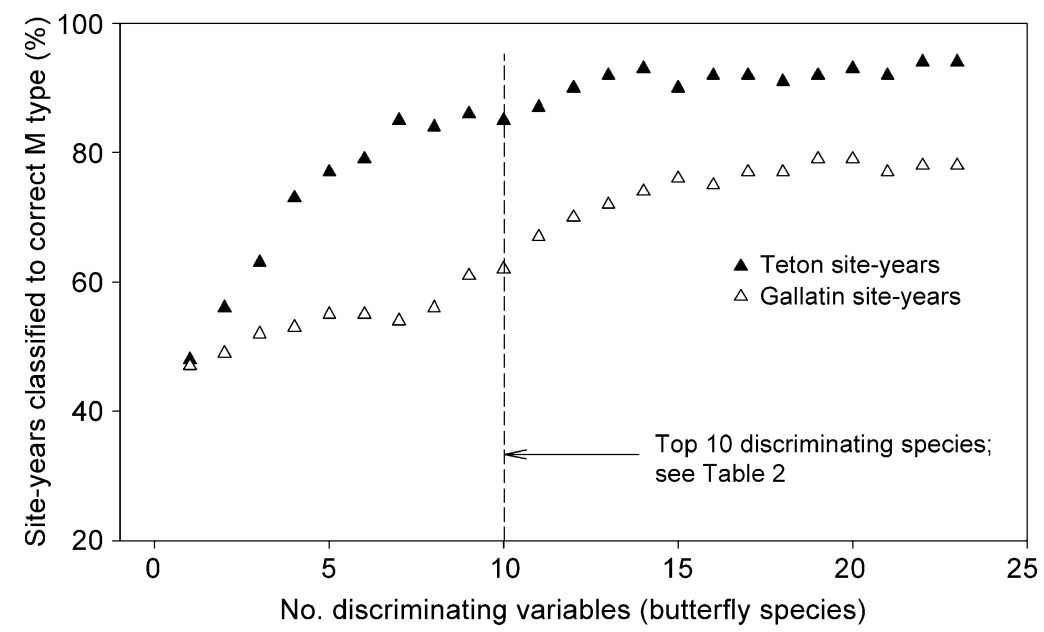

FIG. 4. Discriminant analysis performance curves comparing the Gallatins and Tetons using species compositions of butterflies to discriminate among meadow types (M types). As more discriminating variables (butterfly species) were added to the model (in stepwise fashion), more site-years were correctly classified to known M type.

For individual species, we used Student's $t$ tests to determine which species of birds and butterflies were significantly more abundant in certain hydrological groups, pooled over $\mathrm{M}$ types. These groups were termed hydric (M1s and M2s pooled), mesic (M3s and M4s), and xeric (M5s and M6s).

\section{Predictability of ecological communities}

To estimate community-level predictability, we used bird and butterfly species compositions to perform discriminant analyses (DAs), which classified site-years into $\mathrm{M}$ types based on relative species abundances. The more species we used as discriminating variables, the more site-years were classified as the correct $M$ type. Discriminating performance can be quantified and tested among DA models with a jackknife validation technique. Also known as cross validation, this technique removes a single sampling entity from the data, derives classification functions from the remaining data set, and then applies those functions to the removed entity to predict its category (in this case, $M$ type). By plotting the percentage of site-years correctly classified (100 misclassification \%) by the number of discriminating variables (species) included in the analysis, we generated "performance curves." Each curve reached an asymptote (at or below 100\%) at the point where additional species do not improve the discriminating performance of the DA (Fig. 4). These curves were then qualitatively compared among taxa and regions to determine how consistent each community's component species remained in their respective habitat types. The first 10 species chosen in a stepwise manner with PROC STEPDISC in SAS version 8.2 (SAS Institute 1999) were also noted to compare with species-habitat associations identified in the previous section. Choosing 10 species was based on a subjective observation of the performance curves; at 10 species, a high degree of M-type discrimination was accomplished relative to the asymptote, especially in the Teton region.

To assess how well species composition corresponded with our remotely sensed classification scheme of $M$ types, we used nonmetric multidimensional scaling (NMDS; Kruskal 1964), an unconstrained ordination technique. Nonmetric multidimensional scaling is unconstrained in the sense that the configuration of siteyears (points) observed in the ordination plot is derived entirely from the species abundance data and is not dependent on any hypothesized underlying gradient data. Site-years closer to each other on the ordination plots have more similar species compositions than those farther apart. Function "isoMDS" from the MASS library in the R-project (R Development Core Team 2004) statistical package was used for the NMDS. Since this is a distance-based ordination (rather than eigenanalysis-based), we chose the Bray-Curtis dissimilarity index (Faith et al. 1987) as our measure of ecological distance.

We then overlaid hypothesized gradients or environmental variables onto the NMDS plots without disrupting the configuration of the original ordinations using function "envfit" from the VEGAN library (Dixon 2003). First, we added $M$ type as a categorical variable, which overlaid labeled centroids for each M type on the plot. Because each point in the ordination represented a site-year combination, the four survey years were also overlaid as categorical variables to look for temporal changes in species composition. Finally, we overlaid NDVI as a continuous variable to determine if it was correlated with any temporal shifts in species compositions across years. We evaluated temporal and NDVI effects on species composition both among and between $M$ types for all four taxon-region data set combinations. 
Combining the function "envfit" with NMDS (or any other ordination) provides a unique compromise between the classical "subjective" evaluations of unconstrained ordination (Økland 1996) and the hypothesis-driven constrained methods such as the now-popular canonical correspondence analysis (CCA; Ter Braak 1986). Overlaying environmental (gradient) variables on an ordination using "envfit" also generates an $R^{2}$ measure of fit and a "significance" value based on the probability that random permutations of the environmental variables would yield a higher degree of fit than the true environmental variables.

It is important to note, however, that environmental variables overlaid with "envfit" are independently modeled effects and not part of a globally modeled combination of effects such as that used by CCA. Therefore, one effect cannot be evaluated in the context of or after having "partialled" out the variation of others. It is also important to note that NMDS plots are simply maps reflecting ecological dissimilarity; their axes are arbitrary and do not extract orthogonal variation from a data set the way an eigenanalysisbased ordination does. A common difficulty in the latter form of ordination is deciding from which axis to interpret your site scores. With NMDS and function "envfit" all dimensions are considered simultaneously, and the original ordination's configuration is left intact.

We used this two-step method (NMDS followed by factor fitting) on each of our four taxon regions, using NDVI, $M$ type, and year as factors. In the Gallatin butterfly case, where the year factor had a significant effect on the ordination, we performed an additional analysis on the subset of $\mathrm{M}$ types that showed the most consistent time-related trends.

\section{Results}

\section{Landscape differences between regions}

The major landscape differences between our two study regions were mean patch size and edge-to-area ratio of patches (Debinski et al. 2001). The Gallatins (total area $=4035$ ha, total patches $[N]=2181$, mean $=1.85$ ha) have significantly smaller patches $(t=$ 5.929 , df $=1595, P<0.001)$ and higher edge ratios $(t=7.589, \mathrm{df}=2443, P<0.001)$ than the Tetons (total area $=3683$ ha, total patches $[N]=1148$, mean $=3.21$ ha).

\section{NDVI and climate trends}

The Gallatins showed more among-year variability in the NDVI than the Tetons, as evidenced by their $F$ ratios (Gallatins, $F=1.87$, df $=3,96, P=0.140$; Tetons, $F=1.02$, df $=3,96, P=0.386$ ). In an ANOVA relating NDVI to region, year, and M-type effects, the NDVI did not differ between regions (Gallatins and Tetons, $F=1.16$, df $=1,199, P=0.282$ ). The NDVI did not differ between M1s, M2s, and M3s (hydric to mesic gradient), but those three as a group were higher than M5s, which in turn were higher than M6s (xeric), using separately run contrasts between these groups in the ANOVA (Figs. 2 and 3, $F=240.70$, df $=4,199$, $P<0.001)$. The NDVI differed among years $(F=$ 16.05 , df $=3,199, P<0.001$ ), with the greatest difference between 1997 and 2000 (Tukey's HSD with alpha $=0.05)$. Climate trends over the long term (1985-2003) were stochastic, but within a limited range for most years, showing a trend towards increasing precipitation from 1990 to 1995 followed by a noticeable drying trend from 1996 to 2001 (Fig. 1).

\section{Identifying species-habitat relationships and community predictability}

We identified species that were significantly more abundant in wet, mesic, or dry meadows (Table 1) and characterized them as having a hydrological affinity to these pooled classifications. The top 10 species selected by the stepwise DA analysis (Table 2) were considered to be those whose abundance had the greatest effect on separating $M$ types.

We used DA to analyze how tightly sites clustered by species composition. This worked especially well for butterflies in the Tetons. We also plotted DA performance curves to examine how many species were required to correctly classify site-years by $\mathrm{M}$ type. The DA performance curves were qualitatively higher for butterflies than for birds in both the Gallatins and the Tetons. While the butterfly species composition could be used to obtain $90-100 \%$ accuracy in classifying M types, birds barely reached $70 \%$ in the Gallatins and over $90 \%$ in the Tetons. The DA performance curves were higher in the Tetons than in the Gallatins for both taxa, but more so for the butterflies (Fig. 4), where Gallatin sites reached maximal percentage of site-years correctly classified at much lower levels $(\sim 80 \%)$ than the Tetons (100\%).

By combining the DA performance curves with the NMDS ordinations overlaid with M-type centroids (and their associated $R^{2}$ values: Table 3 ), we can rank the M-type affinities by taxon-region. That is, both methods of comparison indicate butterflies to be more predictable in separating $M$ type than birds (in both the Gallatins and Tetons). Furthermore, the Teton birds and butterflies are more predictable in separating $\mathbf{M}$ types than the Gallatin birds and butterflies, respectively.

The NMDS provided a finer resolution of temporal changes in site-specific species composition. In an example ordination plot of Teton butterflies (Fig. 5), each site is coded by $\mathbf{M}$ type. Similar $\mathbf{M}$ types are closely grouped, indicating similar species compositions in those sites. The adjacency and slight overlap in some M types reflect the ordinal nature of our M-type classification scheme. The overlay of $\mathrm{M}$ types as categorical variables are indicated by labels that represent the centroid or mean of that group's ordination scores (coordinates). The categorical year values are represented 
TABLE 1. Bird and butterfly hydrological affinities for the Gallatin and Teton regions of the greater Yellowstone Ecosystem based on relative abundance in different meadow types from 1997 to 2001.

\begin{tabular}{|c|c|c|c|}
\hline \multicolumn{2}{|c|}{ Birds } & \multicolumn{2}{|c|}{ Butterflies } \\
\hline Gallatin region (14 spp.) & Teton region (17 spp.) & Gallatin region (24 spp.) & Teton region (24 spp.) \\
\hline \multicolumn{4}{|l|}{ Hydric } \\
\hline $\begin{array}{l}\text { Geothlypis trichas } \\
\text { Melospiza lincolnii } \\
\text { Passerculus sandwichensis }\end{array}$ & $\begin{array}{l}\text { Euphagus cyanocephalus } \\
\text { Gallinago gallinago } \\
\text { Geothlypis trichas } \\
\text { Passerella iliaca } \\
\text { Melospiza lincolnii } \\
\text { Passerculus sandwichensis } \\
\text { Melospiza melodia } \\
\text { Empidonax traillii } \\
\text { Dendroica petechia }\end{array}$ & $\begin{array}{l}\text { Boloria selene } \\
\text { Erebia epipsodea } \\
\text { Pieris napi } \\
\text { Plebejus saepiolus }\end{array}$ & $\begin{array}{l}\text { Boloria frigga } \\
\text { Boloria selene } \\
\text { Erebia epipsodea } \\
\text { Lycaena hyllus } \\
\text { Phyciodes selenis } \\
\text { Plebejus saepiolus } \\
\text { Speyeria cybele }\end{array}$ \\
\hline $\begin{array}{l}\text { Mesic } \\
\quad(\text { None })\end{array}$ & Zonotrichia leucophyrs & $\begin{array}{l}\text { Coenonympha haydenii } \\
\text { Lycaena helloides } \\
\text { Phyciodes campestris }\end{array}$ & $\begin{array}{l}\text { Glaucopsyche lygdamus } \\
\text { Lycaeides idas } \\
\text { Lycaena helloides } \\
\text { Speyeria mormonia }\end{array}$ \\
\hline \multicolumn{4}{|l|}{ Xeric } \\
\hline $\begin{array}{l}\text { Spizella passerina } \\
\text { Pooecetes gramineus }\end{array}$ & $\begin{array}{l}\text { Spizella breweri } \\
\text { Pooecetes gramineus }\end{array}$ & $\begin{array}{l}\text { Cercyonis oetus } \\
\text { Coenonympha tullia } \\
\text { Lycaena heteronea } \\
\text { Oeneis chryxus } \\
\text { Parnassius phoebus }\end{array}$ & $\begin{array}{l}\text { Cercyonis oetus } \\
\text { Coenonympha tullia } \\
\text { Lycaena heteronea } \\
\text { Plebejus icarioides }\end{array}$ \\
\hline
\end{tabular}

Notes: Meadow types M1 and M2 were pooled as hydric, M3 and M4 as mesic, M5 and M6 as xeric. Species were listed when their abundance in one hydrologic type was significantly higher than both other hydrologic types (Student's $t$, alpha $=0.05)$. The numbers listed in parentheses refer to the total number of species observed in each of the habitat types. Names of bird and butterfly species are listed in scientific format. Common names of birds are listed here in parentheses because bird species are also conventionally published using common names. Birds listed in the table are as follows: Dendroica petechia (Yellow Warbler), Empidonax traillii (Willow Flycatcher), Euphagus cyanocephalus (Brewer's Blackbird), Gallinago gallinago (Common Snipe), Geothlypis trichas (Common Yellowthroat), Melospiza lincolnii (Lincoln's Sparrow), Melospiza melodia (Song Sparrow), Passerella iliaca (Fox Sparrow), Passerculus sandwichensis (Savannah Sparrow), Pooecetes gramineus (Vesper Sparrow), Spizella breweri (Brewer's Sparrow), Spizella passerina (Chipping Sparrow), and Zonotrichia leucophyrs (White-crowned Sparrow).

by plus symbols since they are so close together that their labels would overlap and be indistinguishable. The continuous variable NDVI is represented by an arrow pointing in the direction of its highest rate of increase (see also Figs. 2 and 3, where "low" M types have high NDVI values).

The NMDS plots for birds in both the Gallatins and Tetons were similar to that just described by Teton

TABLE 2. Top 10 discriminating bird and butterfly species in the Gallatins and Tetons.

\begin{tabular}{|c|c|c|c|}
\hline \multicolumn{2}{|c|}{ Birds } & \multicolumn{2}{|c|}{ Butterflies } \\
\hline Gallatin region & Teton region & Gallatin region & Teton region \\
\hline Melospiza lincolnii & Dendroica petechia & Cercyonis oetus & Lycaena heteronea \\
\hline Spizella passerina & Spizella breweri & Lycaena heteronea & Cercyonis oetus \\
\hline Pooecetes gramineus & Geothlypis trichas & Phyciodes campestris & Coenonympha tullia \\
\hline Passerculus sandwichensis & Pooecetes gramineus & Plebejus icarioides & Erebia epipsodea \\
\hline Euphagus cyanocephalus & Passerculus sandwichensis & Erebia epipsodea & Speyeria mormonia \\
\hline Junco hyemalis & Melospiza lincolnii & Parnassius phoebus & Plebejus icarioides \\
\hline Zonotrichia leucophyrs & Passerella iliaca & Oeneis chryxus & Boloria frigga \\
\hline Geothlypis trichas & Euphagus cyanocephalus & Coenonympha haydenii & Plebejus saepiolus \\
\hline Spizella breweri & Zonotrichia leucophyrs & Boloria selene & Lycaena idas \\
\hline Turdus migratorius & Empidonax traillii & Pieris napi & Glaucopsyche lygdamus \\
\hline
\end{tabular}

Notes: These were chosen using the stepwise variable selection option of discriminant analysis (DA) and are listed in the order in which they were entered into the DA model. Discriminant analyses were used to discriminate among meadow types (M types) using species abundances from 1997 to 2001. Names of bird and butterfly species are listed in scientific format. Common names of birds are listed here in parentheses because bird species are also conventionally published using common names. Birds listed in the table are as follows: Dendroica petechia (Yellow Warbler), Empidonax traillii (Willow Flycatcher), Euphagus cyanocephalus (Brewer's Blackbird), Geothlypis trichas (Common Yellowthroat), Junco hyemalis (Dark-eyed Junco), Melospiza lincolnii (Lincoln's Sparrow), Passerella iliaca (Fox Sparrow), Passerculus sandwichensis (Savannah Sparrow), Pooecetes gramineus (Vesper Sparrow), Spizella breweri (Brewer's Sparrow), Spizella passerina (Chipping Sparrow), Turdus migratorius (American Robin), and Zonotrichia leucophyrs (White-crowned Sparrow). 
TABLE 3. Ranking of taxon regions by meadow type (M type) separation based on goodness-of-fit $\left(R^{2}\right)$ from function "envfit" in the VEGAN library for the R-project statistical package (R Development Core Team 2004).

\begin{tabular}{lcc}
\hline \hline Region and taxon & M-type $R^{2}$ & $P$ \\
\hline Teton & & \\
$\quad$ Butterflies & 0.81 & $<0.001$ \\
Birds & 0.65 & $<0.001$ \\
Gallatin & & \\
$\quad$ Butterflies & 0.58 & $<0.001$ \\
Birds & 0.46 & $<0.001$
\end{tabular}

Notes: M-type was used as a categorical variable and fit to a nonmetric multidimensional scaling (NMDS) ordination of site-years with $k=4$ dimensions. Ordinations were based on bird and butterfly Bray-Curtis community similarity. For regions, the Tetons (birds and butterflies) formed "tighter" groups than the Gallatins, and within each region the butterflies formed tighter M-type groups than the birds.

butterflies, namely in their lack of temporal effects. However, the Gallatin butterfly data set warranted further investigation (Fig. 6), because the year centroids showed a greater separation than the other taxon-region plots $\left(R^{2}=0.06, P=0.052\right.$; the low $R^{2}$ value is the result of the overriding fit of data to the M-type gradient, which spreads the NDVI and M-type values of each site-year across the first dimension of the plot, NMDS1).

We therefore replotted the Gallatin butterfly NMDS ordination using only the 1997 and 2000 site-years and connected those points with arrows (Fig. 7). By visual inspection, nearly all arrows in the hydric and mesic meadows are directed upward, showing a similar shift in species composition. We fitted the NDVI values over this ordination (Fig. 7) using "envfit," but the oblique angle to the community shifts did not suggest a relationship between NDVI and the composition changes. The fact that all $\mathrm{M}$ types were included in the plot meant we were showing an NDVI trend that was effectively mimicking the M-type gradient with which it was negatively correlated; that is, M6s are the driest meadows with the lowest NDVI, whereas M1s are the wettest meadows with the highest NDVI. A within-Mtype analysis was needed to reveal any time-related community change related to NDVI.

In order to separate out the M-type gradient from the temporal gradient in NDVI, we plotted the shifts between the most extreme years (1997 and 2000) in the subset of only wet meadows (M1 to M3). We then overlaid year and NDVI vectors (Fig. 8A). We took the same plot and added a single dry meadow type (M5s) to indicate the effect of the dominant M-type/NDVI gradient. The correlation between year and NDVI went from a virtually perfect negative relationship ( $r=$ -1.00 , showing lower NDVI over time) to nearly orthogonal $(r=0)$ by adding the dry meadow type (Fig. $8 \mathrm{~B}$ ), showing the influence of the M-type gradient on this analysis.

\section{DISCUSSION}

\section{Interannual variability in montane meadow patch condition}

Our first objective was to examine interannual changes in patch quality as determined by site-specific NDVI values. Our assumption was that lower NDVI values were associated with lower plant moisture level, lower vegetative biomass, and potentially even lower nectar production. Given that the Gallatins showed more overall among-year NDVI variation than the Te-

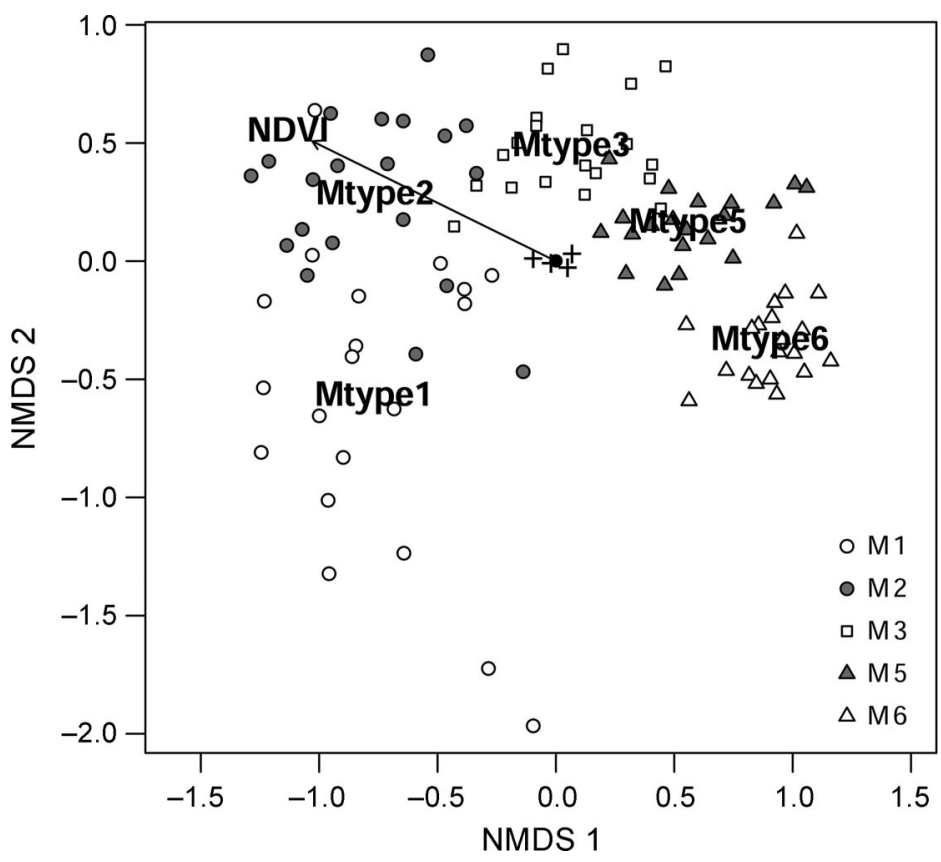

FIG. 5. For Teton butterflies, 1997-2001, 100 site-years were plotted using nonmetric multidimensional scaling (NMDS). The siteyears were coded by meadow type ( $M$ type; indicated by different symbol types), whose mean scores are labeled centroids (categorical variable) by the function "envfit" in the VEGAN library used in the R-project statistical package (R Development Core Team 2004). A second categorical overlay of year is represented by the " +" symbols rather than labels that would been indistinguishable due to their lack of separation. The third overlay is the continuous normalized difference vegetation index (NDVI) variable pointing in the direction of increasing NDVI values at each site-year. 


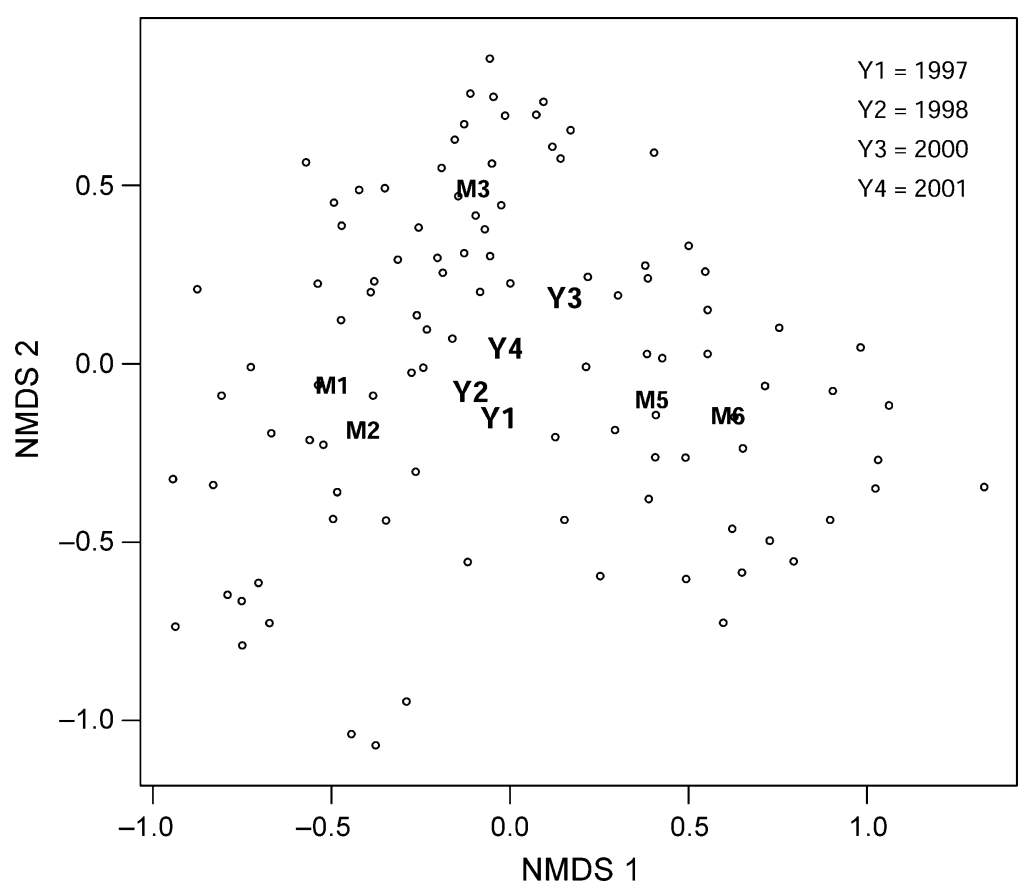

FIG. 6. Nonmetric multidimensional scaling (NMDS) ordination of Gallatin butterflies, 1997-2001, with site-year points de-emphasized to show differences in centroids of survey years. The largest year separation $\left(R^{2}=0.06, P=0.064\right)$ is between 1997 and 2000, which became the pairwise comparison for the rest of our analyses relating temporal community change to the normalized difference vegetation index (NDVI).

tons, we have evidence at a regional scale that our hypothesis of higher variability of NDVI in smaller patches is supported. We also found that in both regions, the greatest decline in NDVI was between 1997 and 2000 (nearly equal to the drop from 1998 to 2000). This period generally coincides with the drying trend we observed in our long-term precipitation data set.

\section{Species-habitat associations}

Our second objective was to identify species-habitat associations. We have identified several key species that have strong habitat associations along the hydrological gradient. When we pooled $\mathrm{M}$ types into three classes (wet, mesic, and dry), several bird and butterfly species showed a significant affinity to those groups as evidenced by their relative abundances (Table 1 ). The Gallatin and Teton regions had similar numbers of such species for mesic and xeric meadows, but the Teton region had several more bird and butterfly species showing an affinity for hydric meadows. This could be due to the landscape differences between the two regions (patch sizes of hydric meadows are much larger in the Tetons). Our stepwise method of DA also revealed those species most responsible for discriminating among habitat types.

\section{Predictability of ecological communities}

The DA performance curves and NMDS ordination techniques allowed us to compare regions at the entire community level without necessarily detailing every species' abundance trends. With long-term data sets, observers vary from year to year, and differences among observers' surveying ability should be taken into account. Multivariate techniques such as DA and NMDS rely on species composition rather than individually modeled species abundance trends. We are assuming that if differences in surveyor ability varied among years, the counts of birds and butterflies maintained consistent species compositions.

Our results allowed us to compare DA performance curves among years, regions, and taxa. We interpreted higher curves as systems with larger mean patch size that show less spillover (movement from a preferred habitat type to an adjacent, less preferable habitat type) and stronger habitat affinities, as seen in our previous work (Debinski et al. 2000). These associations could potentially imply higher reproduction, assuming less time is wasted by individuals in less ideal habitat, where population would be less dense. The Gallatins showed less specific habitat affinities than the Tetons in both bird and butterfly communities. Furthermore, fewer birds showed specific habitat affinities than butterflies in both Gallatin and Teton regions. We expected this for the Gallatins based on known landscape differences (mean patch sizes), and the higher mobility and migratory habits of birds may explain their lower degree of habitat affinity. Birds also respond strongly to the height and structure of shrubby vegetation (Knopf and Sedgwick 1992), and NDVI does not pro- 


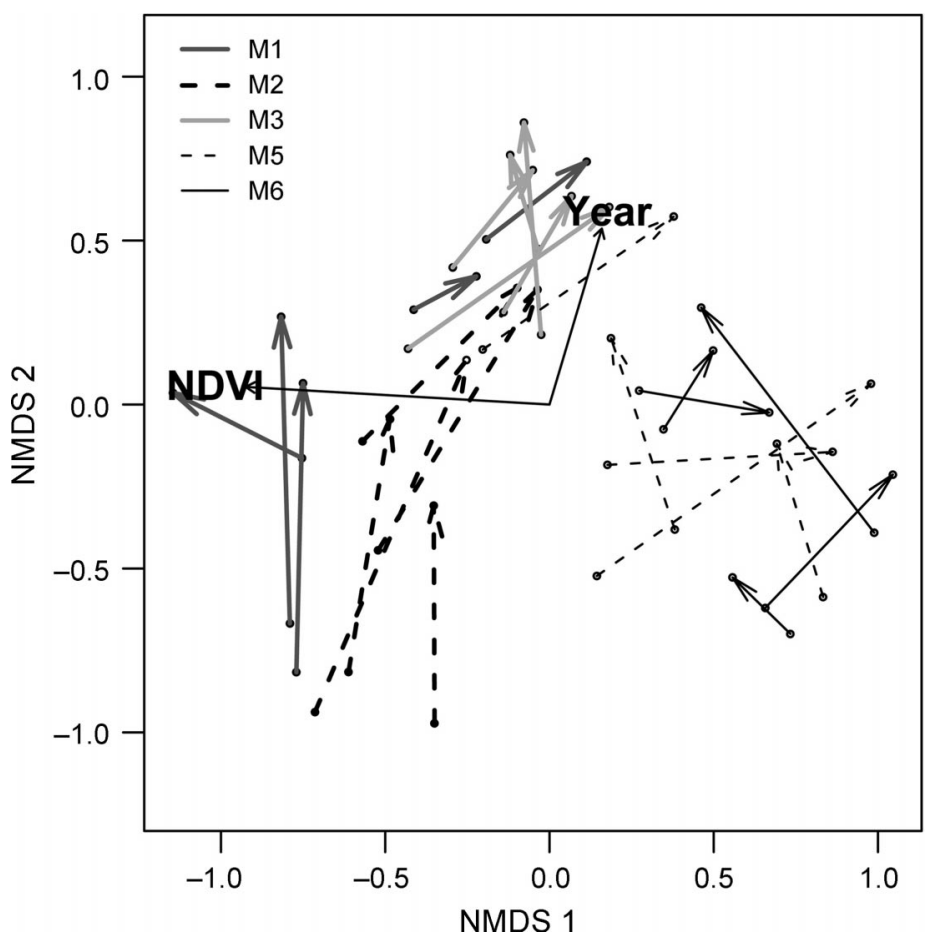

FIG. 7. Nonmetric multidimensional scaling (NMDS) plot of Gallatin butterfly site-years for only 1997 and 2000 fitted with a normalized difference vegetation index (NDVI) and year vector. Different arrow types point from 1997 to 2000 , and the fitted year vector summarizes the individual site-year shifts. The wet meadows (M1, M2, and M3) appear to have a concurrent shift in the same direction, while the dry meadows (M5 and M6) appear randomly oriented. vide enough information to include these variables in the analysis.

\section{Broader applications of integrated ordination techniques}

Ordination techniques designed to detect species composition shifts along an environmental gradient continue to grow in sophistication (e.g., De'ath 1999). Our integrated method of fitting extrinsic factors to unconstrained ordinations is not restricted to specieslevel analysis, but could include higher level taxa, functional guilds, or trophic levels. The extrinsic factors (usually environmental variables) could be replaced with various experimental treatments, such as management practices (e.g., burning regimes and planting mixtures) or surrounding broad-scale landscape variables. In essentially any situation in which several entities (variables) occur in a variety of compositions, this integrated method of ordination and variable fitting is able to (1) arrange sample sites in a meaningful way based on those compositions and (2) detect potential extrinsic factors, either environmental or experimentally applied, that may influence the arrangement of those sites.

\section{Conclusions}

Of the four taxon regions we surveyed, Gallatin butterflies showed the most consistent compositional trends between 1997 and 2000, which coincides with the significant drop in NDVI and precipitation between those years. Fig. 7 highlights the consistency of a trend in NDMS ordination scores between 1997 and 2000, es- pecially in the wet meadows (M1s, M2s, and M3s). When the wet meadows are plotted with NMDS by themselves and fit with an NDVI and year vector, a strong negative correlation was found. This implies that the wet meadows were effectively shifting towards what might be described as a more xeric butterfly community. The mechanism for such a change could be that in years of drought, the soil moisture is decreased, which results in a change in plant community cover in wet meadows. Within each meadow type, plants adapted to drier conditions may flourish, while those adapted to wetter conditions may become dessicated or decrease in biomass. Because butterflies can move throughout this matrix of different meadow types selecting nectar and host plants and sites for oviposition or diapause, one point in the landscape may show differences in the local butterfly community among years. Thus, butterfly species adapted to wetter conditions, such as Boloria frigga, Boloria selene, Phyciodes campestris, Lycaena helloides, and Coenonympha haydenii, may be especially important to monitor for decreasing trends over time.

We have shown some striking patterns of association between species abundance and NDVI and have taken a new approach to the analysis of ecological community data from a temporal perspective. Previous authors have used bird or butterfly communities to identify indicators (Morrison 1986, Kremen 1992) and even conducted this research in the context of environmental gradients at a fine geographic scale (e.g., Fleishman et al. 1998, 2000) and/or climate change at a coarse geographic scale (Parmesan et al. 1999, Root et al. 2003). Here we have linked community changes with climate 
A) Gallatin butterfly shifts in wet meadows only

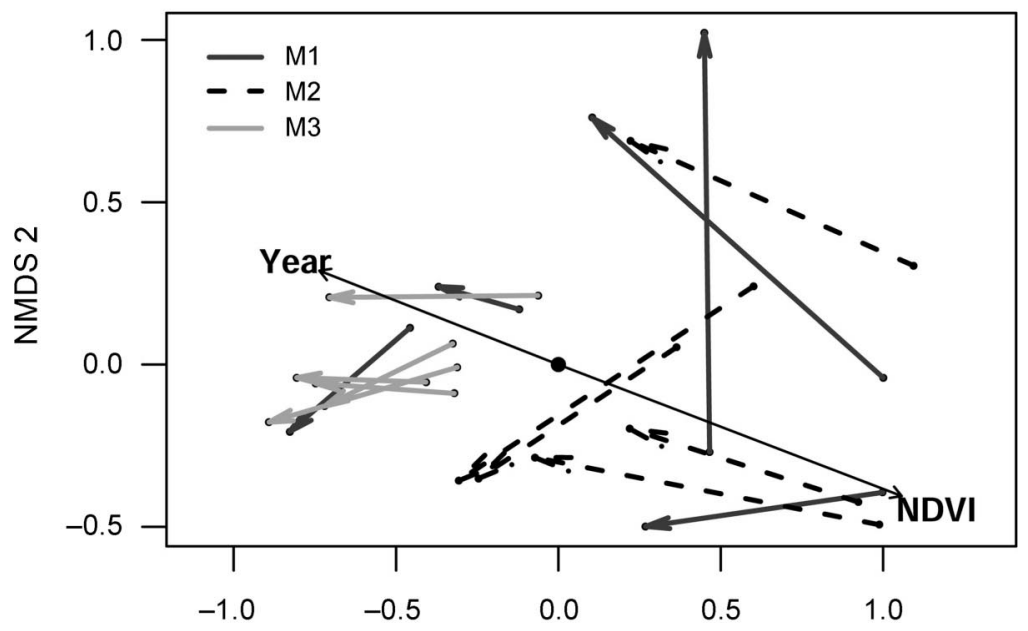

B) Gallatin butterfly shifts with M5s added

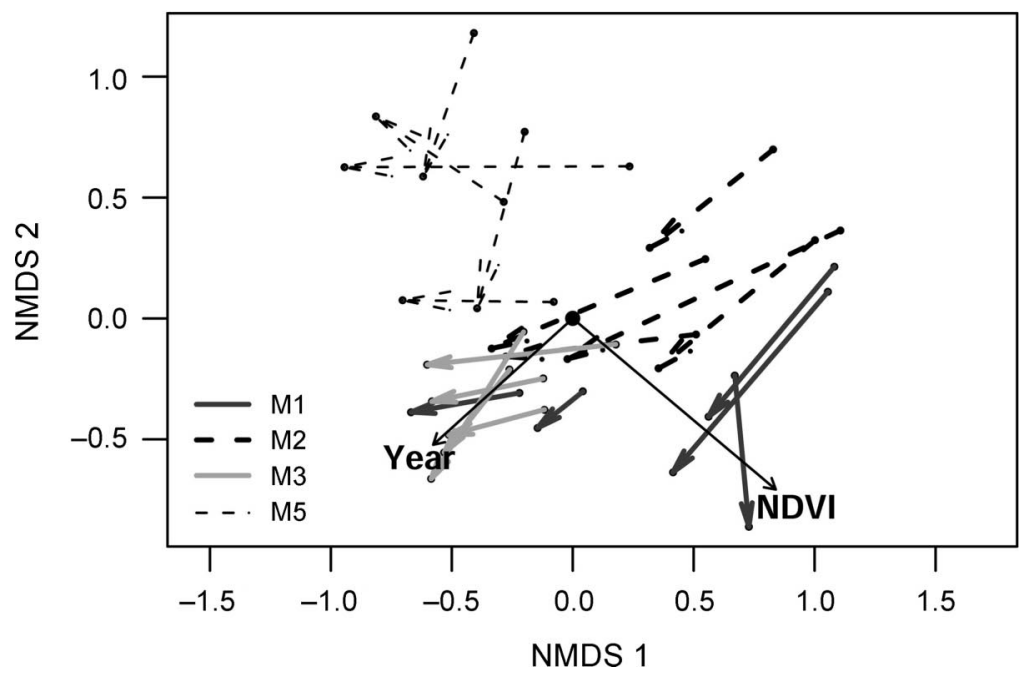

FIG. 8. (A) Nonmetric multidimensional scaling (NMDS) ordination plot of Gallatin butterfly site-years for only 1997 and 2000 and only wet meadows (M1, M2, and M3). Arrows point from 1997 to 2000, and the fitted year vector (summarizing the individual site-year shifts) is pointing opposite that of the normalized difference vegetation index (NDVI), indicating a nearly perfect negative correlation $(r \approx-1.00)$. (B) The same procedure showing the addition of a single dry meadow type (M5), which has a distinctly different NDVI than the wet meadows (see Table 3 ). The new NDVI vector is thus dominated by the M type differences, and correlation between year and NDVI becomes nearly orthogonal.

change at a fine geographic scale. It was fortuitous that the period that we chose to examine was a time during which the ecosystem was experiencing a drying trend. We must point out that the period of analysis is only a small slice in time, and there are other causative factors affecting these meadow communities such as longer-term weather patterns, interspecific interactions, environmental disturbances, and the patterns of patch size and patch distribution throughout the landscape. Additional years of study will allow us to tease out the relative effects of each of these factors with a higher level of sophistication.

However, meadows across the spectrum of hydrology, not just the hydric sites, showed significant NDVI changes over time. If certain meadow types decrease in size over the long term, the current Gallatin landscape could potentially serve as a future representation of the Teton landscape, but only in the mesic to hydric range. We believe that these regions are key areas to continue monitoring from the perspective of global climate change. Understanding how interannual climate variability affects this pristine ecosystem will aid us in projecting the implications of climate variability and change at a more global scale.

\section{ACKNOWLEDGMENTS}

Sincere thanks go out to the University of Wyoming, National Park Service Research Center (AMK Ranch: Henry Harlow, director) for funding and accommodating our re- 
search team over the years. We also thank Brian Miller of the Denver Zoological Foundation for funding, collaboration, and general camaraderie. Data collection during 1997-2000 was funded by a grant from the Environmental Protection Agency (EPA) through their Ecological Assessment and Restoration program. Although funded by the EPA (through grant 96-NCERQA-1A to Debinski et al.), it has not been subjected to the Agency's peer review and therefore does not necessarily reflect the views of the Agency and no official endorsement should be inferred. Additional funding was provided by the Iowa Space Grant Consortium and the Grand Teton Natural History Association. Statistical consulting was provided by Kirk Moloney and Philip Dixon of Iowa State University. This manuscript was improved by the recommendations of M. Turner, C. Boggs, E. Fleishman, and two anonymous reviewers. Finally, thanks to the many field technicians who have helped over the years, especially Amanda Hetrick and Julie Perret.

\section{Literature Cited}

Achard, F., and F. Blasco. 1990. Analysis of vegetation seasonal evolution and mapping of forest cover in West Africa with the use of NOAA AVHRR HRPT data. Photogrammetric Engineering and Remote Sensing 56:1359-1365.

Becker, F., and B. J. Choudhury. 1988. Relative sensitivity of Normalized Difference Vegetation Index (NDVI) and Microwave Polarization Difference Index (MPDI) for vegetation and desertification monitoring. Remote Sensing of Environment 24:297-311.

Brown, J. H., T. H. Valone, and C. G. Curtin. 1997. Reorganization of an arid ecosystem in response to recent climate change. Proceedings of the National Academy of Science USA 94:9729-9733.

Cairns, J., Jr. 1986. The myth of the most sensitive species. BioScience 36:670-672.

Cardillo, M., D. W. Macdonald, and S. P. Rushton. 1999. Predicting mammal species richness and distributions: testing the effectiveness of satellite-derived land cover data. Landscape Ecology 14:423-435.

De'ath, G. 1999. Principal curves: a new technique for indirect and direct gradient analysis. Ecology 80:2237-2253.

Debinski, D. M., M. E. Jakubauskas, and K. Kindscher. 1999. A remote sensing and GIS-based model of habitats and biodiversity in the Greater Yellowstone Ecosystem. International Journal of Remote Sensing 20:3281-3292.

Debinski, D. M., M. E. Jakubauskas, and K. Kindscher. 2000. Montane meadows as indicators of environmental change. Environmental Monitoring and Assessment 64:213-225.

Debinski, D. M., M. E. Jakubauskas, K. Kindscher, E. H. Saveraid, and M. Borgognone. 2002. Predicting meadow communities and species occurrences in the Greater Yellowstone Ecosystem. Pages 499-506 in J. M. Scott, P. J. Heglund, M. Morrison, M. Raphael, J. Haufler, and B. Wall, editors. Predicting species occurrences: issues of scale and accuracy. Island Press, Covello, California, USA.

Debinski, D. M., and J. A. Pritchard. 2002. A field guide to butterflies of the Greater Yellowstone Ecosystem. Roberts Rinehart, Boulder, Colorado, USA.

Debinski, D. M., C. Ray, and E. H. Saveraid. 2001. Species diversity and the scale of the landscape mosaic: do scales of movement and patch size affect diversity? Biological Conservation 98:179-190.

Dennis, R. L. 1993. Butterflies and climate change. Manchester University Press, New York, New York, USA.

Dixon, P. 2003. VEGAN, a package of R functions for community ecology. Journal of Vegetation Science 14:927-930.

Du, Y., P. M. Teillet, and J. Cihlar. 2002. Radiometric normalization of multitemporal high-resolution satellite images with quality control for land cover change detection. Remote Sensing of Environment 82:123-134.
Faith, D. P., P. R. Minchin, and L. Belbin. 1987. Compositional dissimilarity as a robust measure of ecological distance. Vegetatio 69:57-68.

Fitter, A. H., and R. S. R. Fitter. 2002. Rapid changes in flowering time in British plants. Science 296:1689-1691.

Fleishman, E., G. T. Austin, and A. D. Weiss. 1998. An empirical test of Rappaport's rule: elevational gradients in montane butterfly communities. Ecology 79:2482-2493.

Fleishman, E., J. P. Fay, and D. D. Murphy. 2000. Upsides and downsides: contrasting topographic gradients in species richness and associated scenarios for climate change. Journal of Biogeography 27:1209-1219.

Fleishman, E., R. Mac Nally, and J. P. Fay. 2003. Validation tests of predictive models of butterfly occurrence based on environmental variables. Conservation Biology 17:806817.

Fleishman, E., R. Mac Nally, J. P. Fay, and D. D. Murphy. 2001. Modeling and predicting species occurrence using broad-scale environmental variables: an example with butterflies of the Great Basin. Conservation Biology 15:16741685 .

Furby, S. L., and N. A. Campbell. 2001. Calibrating images from different dates to 'like-value' digital counts. Remote Sensing of Environment 77:186-196.

Gallo, K. P., and J. Eidenshink. 1988. Differences in visible and near-IR responses and derived vegetation indices for the NOAA-9 and NOAA-10 AVHRRs: a case study. Photogrammetric Engineering and Remote Sensing 54:485490.

Graetz, R. D. 1990. Remote sensing of terrestrial ecosystem structure: an ecologist's pragmatic view. Pages 5-30 in R. J. Hobbs and H. A. Mooney, editors. Remote sensing of biosphere functioning. Ecological Studies 79. SpringerVerlag, New York, New York, USA.

Hepinstall, J. A., W. B. Krohn, and S. A. Sader. 2002. Predicting meadow communities and species occurrences in the Greater Yellowstone Ecosystem. Pages 499-506 in J. M. Scott, P. J. Heglund, M. Morrison, M. Raphael, J. Haufler, and B. Wall, editors. Predicting species occurrences: issues of scale and accuracy. Island Press, Covello, California, USA.

Jakubauskas, M. E., and D. M. Debinski. 1995. An integrated spectral and ecological approach to mapping forest and meadow communities of the Greater Yellowstone Ecosystem. Association of American Geographers Annual Meeting, Chicago, Illinois, USA.

Jakubauskas, M. E., K. Kindscher, and D. M. Debinski. 1998. Multitemporal characterization and mapping of montane sagebrush communities using Indian IRS LISS-II imagery. Geocarto International 13:65-74.

Jensen, J. R. 1983. Urban/suburban land use analysis. Pages 1571-1666 in J. R. Jensen, editor. Manual of remote sensing. Second edition. Volume 2. American Society of Photogrammetry, Falls Church, Virginia, USA.

Jensen, J. R. 2000. Remote sensing of the environment: an earth resource perspective. Prentice-Hall, Upper Saddle River, New Jersey, USA.

Kerr, J. T., T. R. E. Southwood, and J. Cihlar. 2001. Remotely sensed habitat diversity predicts butterfly species richness and community similarity in Canada. Proceedings of the National Academy of Science 98:11365-11370.

Kindscher, K., A. Frasier, M. E. Jakubauskas, and D. M. Debinski. 1998. Identifying wetland meadows in Grand Teton National Park using remote sensing and average wetland values. Wetlands Ecology and Management 5:265273.

Knopf, F. L., and J. A. Sedgwick. 1992. An experimental study of nest-site selection by Yellow Warblers. Condor 94: 734-742. 
Kremen, C. 1992. Assessing the indicator properties of species assemblages for natural areas monitoring. Ecological Applications 2:203-217.

Kruskal, J. B. 1964. Nonmetric multidimensional scaling: a numerical method. Psychometrika 29:115-129.

Lancaster, J., D. Mouat, R. Kuehl, W. Whitford, and D. Rapport. 1996. Time series satellite data to identify vegetation response to ecosystem stress as an indicator of ecosystem health. Proceedings, Shrubland Ecosystem Dynamics in a Changing Environment. General Technical Report INTGTR-338. U.S. Department of Agriculture, Forest Service, Intermountain Research Station, Ogden, Utah, USA.

Landres, P. B., J. Verner, and J. W. Thomas. 1988. Ecological uses of vertebrate indicator species: a critique. Conservation Biology 2:316-329.

Lighthill, J., G. Holland, W. Gray, C. Landsea, G. Craig, J. Evans, Y. Kurihara, and C. Guard. 1994. Global climatechange and tropical cyclones. Bulletin of the American Meteorological Society 75:2147-2157.

McLaughlin, J. F., J. J. Hellman, C. L. Boggs, and P. R. Ehrlich. 2002. Climate change hastens population extinctions. Proceedings of the National Academy of Sciences USA 99:6070-6074.

Morrison, M. L. 1986. Bird populations as indicators of environmental change. Current Ornithology 3:429-451.

Nearing, M. A. 2001. Potential changes of rainfall erosivity in the U.S. with climate change during the 21 st century. Journal of Soil and Water Conservation 56:229-232.

Nearing, M. A., F. F. Pruski, and M. R. O’Neal. 2004. Expected climate change impacts on soil erosion rates: a review. Journal of Soil and Water Conservation 59:43-48.

Økland, R. H. 1996. Are ordination and constrained ordination alternative or complementary strategies in general ecological studies? Journal of Vegetation Science 7:289292.

O’Neill, R. V., C. T. Hunsaker, K. B. Jones, K. H. Riitters, J. D. Wickham, P. Schwartz, I. A. Goodman, B. Jackson, and W. S. Baillargeon. 1997. Monitoring environmental quality at the landscape scale. BioScience 47:513-520.

Parmesan, C., et al. 1999. Poleward shifts in geographical ranges of butterfly species associated with regional warming. Nature 399:579-583.

Parmesan, C., and G. Yohe. 2003. A globally coherent fingerprint of climate change impacts across natural systems. Nature 421:37-42.

Pavlidis, Y. A., and F. A. Shcherbakov. 2002. Possible ways of the development of coasts and shelves in the Russian inland seas under the condition of climate warming and sea level rise. Oceanology 42:868-876.

Pollard, E., and T. J. Yates. 1995. Monitoring butterflies for ecology and conservation. Chapman and Hall, London, UK

Pullin, A. S. 1995. Ecology and conservation of butterflies. Chapman and Hall, London, UK.

R Development Core Team. 2004. R: a language and environment for statistical computing. R Foundation for Statistical Computing, Vienna, Austria.

Roller, N. E., and J. E. Colwell. 1986. Coarse-resolution satellite data for ecological surveys. BioScience 36:468475.

Romme, W. H., and M. G. Turner. 1991. Implications of global climate change for biogeographic patterns in the
Greater Yellowstone Ecosystem. Conservation Biology 5: 373-386.

Root, T. L., J. T. Price, K. R. Hall, S. H. Schneider, C. Rosenzweig, and J. A. Pounds. 2003. Fingerprints of global warming on wild animals and plants. Nature 421:57-60.

Rotenberry, J. T. 1985 . The role of habitat in avian community composition: physiognomy or floristics? Oecologia 67:213-217.

Salt, G. W. 1957. An analysis of avifaunas in the Teton mountains and Jackson Hole, Wyoming. Condor 59:373-393.

SAS Institute. 1999. SAS/STAT user's guide. Version 8.2. SAS Institute, Cary, North Carolina, USA.

Saveraid, E. H., D. M. Debinski, K. Kindscher, and M. E. Jakubauskas. 2001. A comparison of satellite data and landscape variables in predicting bird species occurrences in the Greater Yellowstone Ecosystem. Landscape Ecology 16:71-83.

Schultz, P. A., and M. S. Halpert. 1993. Global correlation of temperature, NDVI and precipitation. Advances in Space Research 13:277-280.

Steele, B. B., R. L. Bayn, Jr., and C. V. Grant. 1984. Environmental monitoring using populations of birds and small mammals: analysis of sampling effort. Biological Conservation 30:157-172.

Taper, M. L., K. B. Gaese, and J. H. Brown. 1995. Individualistic responses of bird species to environmental change. Oecologia 101:478-486.

Teng, W. L. 1990. AVHRR monitoring of U.S. crops during the 1988 drought. Photogrammetric Engineering and Remote Sensing 56:1143-1146.

Ter Braak, C. J. F. 1986. Canonical correspondence analysis: a new eigenvector technique for multivariate direct gradient analysis. Ecology 67:1167-1179.

Thomas, C. D., et al. 2004. Extinction risk from climate change. Nature 427:145-148.

Ustin, S. L., M. O. Smith, and J. Adams. 1993. Remote sensing of ecological processes: a strategy for developing and testing ecological models using spectral mixture analysis. Pages 339-357 in J. R. Ehleringer and C. B. Field, editors. Scaling ecological processes: leaf to globe. Academic Press, San Diego, California, USA.

Warren, M. 1999. Poleward shift of butterfly species' ranges associated with regional warming. Nature 399:579-583.

Wiens, J. A., and J. T. Rotenberry. 1981. Habitat associations and community structure of birds in shrubsteppe environments. Ecological Monographs 51:21-41.

Wiens, J. A., J. T. Rotenberry, and B. Van Horne. 1987. Habitat occupancy patterns of North American shrubsteppe birds: the effects of spatial scale. Oikos 48:132-147.

Yang, L., B. K. Wylie, L. L. Tieszen, and B. C. Reed. 1998. An analysis of relationships among climate forcing and time-integrated NDVI of grasslands over the U.S. Northern and Central Great Plains. Remote Sensing of Environment 65:25-37.

Yang, W., L. Yang, and J. W. Merchant. 1997. An assessment of AVHRR/NDVI-ecoclimatological relations in Nebraska, U.S.A. International Journal of Remote Sensing 18:21612180.

Yuan, D., and C. D. Elvidge. 1996. Comparison of relative radiometric normalization techniques. Journal of Photogrammetry and Remote Sensing 51:117-126. 